\title{
Research on Measure of Noise Trading in Stock Market Based on EGARCH-M Model
}

\author{
Jin Feng, Dengpeng Lin, Xiangbin Yan \\ School of Management \\ Harbin Institute of Technology \\ Harbin, China \\ linzee2011@gmail.com
}

\begin{abstract}
The impact of noise on stock market is one of the main reasons for inefficiency of information, and deviation of stock price. The measure of noise trading is beneficial for judgment of stock value. This paper has authenticated the existence of noise trading in SHSE A-share market through the variance ratio test method. Then the EGARCH-M model of stock price and trading volume has been established, to authenticate the asymmetric effect of the impact of information. On this basis, this paper utilized the fitting result of the model to separate noise trading, and then build the measure indexes of noise risk and noise component. It has broken through the limitations of previous methods for measure of noise trading.
\end{abstract}

Keywords- noise trading; EGARCH-M model; asymmetric effect; noise risk; noise component

\section{INTRODUCTION}

Noise in the stock market is considered as the reason for reduction of the information's efficiency, but how to measure the noise of market reasonably is still in the exploratory stage. Market trading volume is decided by information and noise, but it's difficult to distinguish these two parts, no matter theoretically or on practice. How to determine the component of noise and its risk, has an important significance for market regulation and investment decision-making.

\section{A. The Concept and Causes of Noise Trading}

The noise in stock market refers to the information which leads to severe deviation between price of asset or portfolio and their expected prices, the concept was put forward by F. Black in 1986 [1]. D. J. Bradford et al. have found that volatility of stock price could not be explained by changes in fundamentals at most of the time; and asset price responded to not only the information, but also irrational "noise trading" [2]. About the definition of noise traders, D. James and G. Gary pointed out that noise trader referred to investors who made investment decision based on noise [3]. P. Frederic regarded noise traders as investment-subjects containing unpredictable faith [4]

Although F. Black introduced and defined the noise trading, and asserted that noise trading was important component in securities market, he did not explain the cause of noise trading [1]. B. W. Gregory pointed out that the most basic characteristics of noise traders was irrational, they took unified action based on noise [5]. The direct impact of noise trading on the market is challenge to the efficient market hypothesis (EMH) which was introduced and deepen by $\mathrm{M}$. G. Burton and F. F. Eugene in 1970 [6]. The generation mechanism of noise and its long-term existence lead to the failure of EMH.

\section{B. Research on Measure of Noise Trading}

How to quantify the noise, and examine its influence on the market, has become an important research-subject of behavioral finance. The first model to quantify noise trading was called as noise traders' model. It was put forward by D. J. Bradford, namely the DSSW model [7]. The model was set up on this basis: there were rational traders and noise traders in the market. Noise traders made trades according to noise that filled the market, and then posed risk.

At empirical level, much of the research has measured noise trading. These studies usually measured noise though behavioral asset pricing model (BAPM) and capital asset pricing model (CAPM). S. Wang and W. Li calculated the risk of stock in CAPM and BAPM, and regarded the difference between them as noise trader risk (NTR) [8]. Other related research are mostly in the same patterns. It's necessary to build momentum index (DVI) which can reflect noise trading in these measure models, such as research of B. Meng [9] and X. Xiao [10] et al.

However, there are following defects in these measure methods of noise trading:

First of all, doubt still exists in the feasibility of CAPM and BAPM, such as X. Chen's study had shown that CAPM was invalid in Chinese stock market [11].

Second, it's difficult to construct DVI index. DVI must satisfy the continuity requirements for a replacement of the index in CAPM. While it's almost impossible to select a certain percentage of stocks as DVI index by sorting turnover rates through all stocks every day, or cannot meet the requirement of timely adjustment according to the "sample stocks" in different situations, either. There is a large error in previous studies which adopted constituent stocks (such as SHSE 50, SHSE 180, etc.) as the DVI index.

Third, the calculation of noise trader risk (NTR) is meaningless. In previous empirical research, NTR is based on the long-term performance of market, as a result, it cannot reflect the market scale and risk of noise trading timely. 
In order to solve these problems, this paper fits the change of price and volume by establishing econometric model, to separate noise trading from them, and then establishes measure indexes of noise risk and noise components.

\section{TeSt AND MEASURE MOdel OF NOISE TRAdING}

We must be clear that the impact of information is asymmetrical before the study on noise trading. Asymmetric shock refers to the impact of the good news and bad news on stock price is different. Y. Zhou and X. Zhao verified the asymmetric effect of information's impact on asset prices [12].

It's a reference that the inspection method of market effectiveness to test of noise's existence. This article adopts the variance ratio method which was put forward by L. W. Andrew and M. A. Craig [13], to test the existence of noise, and applies EGARCH-M model to verify the asymmetric impact of information, and to establish the measure indexes of noise component and noise risk.

$\mathrm{ARCH}$ model refers to the autoregressive conditional heteroscedastic model which was put forward by the E. F. Robert [14], and extended to be generalized ARCH model by B. Tim [15], namely GARCH model. N. B. Daniel proposed the EGARCH model [16] which was based on the more flexible hypothesis than GARCH model. Conditional variance equation of EGARCH model is as follows:

$$
\ln \left(\sigma_{t}^{2}\right)=\omega+\beta \ln \left(\sigma_{t-1}{ }^{2}\right)+\alpha\left|\frac{u_{t}}{\sigma_{t-1}}-\sqrt{2 / \pi}\right|+\gamma \frac{u_{t-1}}{\sigma_{t-1}}
$$

Where $\ln \left(\sigma_{t}^{2}\right)$ is the logarithmic of conditional variances $\sigma_{t}^{2}$, which is able to describe the size of the asymmetric effect. $\omega$ is constant term, $\alpha, \beta$ and $\gamma$ are coefficients; $u_{t}$ is residual. It can be proved that there is asymmetric shock as long as $\gamma \neq 0$.

In this article, we need to use residual error sequence which comes from the fitting model to realize the separation of noise trading, which means to inspect the influence of condition variance equation to the mean equation, it adds conditional variances in the mean equation on the basis of EGARCH model, constitutes the EGARCH-M model. M item of the mean equation must comply with Akaike information criterion and Schwarz information criterion, namely the reduction of AIC and SC. In addition, M item has many choices, such as condition of variance, standard deviation, $\ln \left(\sigma_{t}^{2}\right)$ and etc. In the mean equation, the relationship between two periods of the time series is uncertain, namely $\mathrm{M}$ item is likely to be negative or positive, there is minus sign only in $\ln \left(\sigma_{t}^{2}\right)$ in the choices of $\mathrm{M}$; In addition, we found that other $M$ items cannot pass the examine of validation after repeated experiments, this article agrees to choose $\ln \left(\sigma_{t}^{2}\right)$ to be item $\mathrm{M}$ for these reasons. The EGARCH-M model is very effective in measure of noise trading for its applicability and convenience, and it is a meaningful reference for the quantification of behavioral finance.

\section{MEASURE INDEX OF NOISE RISK}

\section{A. Data}

In this section, we choose the SHSE A-share index between January 2008 and June 2013, data from Resset database. Then calculate the logarithm yield rate of day $t$, namely $r_{t}$. The expression is:

$$
r_{t}=\ln P_{t}-\ln P_{t-1}
$$

Where $P_{t}$ is SHSE A-share index of day $t$.

First of all, we need to describe intuitively the statistical features of the data. Upon examination, the data disobeys normal distribution from the perspective of the skewness and kurtosis of the data.

The result of variance ratio test supports the existence of noise trading at statistical level. We can calculate the variance ratio of $r_{t}$ by Matlab both in the conditions of homoscedasticity $\left(Z_{1}\right)$ and heteroscedasticity $\left(Z_{2}\right)$, where $q$ is the lag phase. The results are shown in table 1 .

TABLE 1. Results of VARIANCE RATIO TEST

\begin{tabular}{c|l|r|r}
\hline $\boldsymbol{q}$ & $\mathbf{V R}$ & $\mathbf{Z}_{\mathbf{1}}$ & \multicolumn{1}{c}{$\mathbf{Z}_{\mathbf{2}}$} \\
\hline 2 & 0.5021 & -17.3773 & -10.3508 \\
\hline 3 & 0.3227 & -15.8557 & -9.8105 \\
\hline 4 & 0.2399 & -14.1794 & -9.0844 \\
\hline 5 & 0.2007 & -12.7327 & -8.3834 \\
\hline 10 & 0.0997 & -9.3056 & -6.5282 \\
\hline 15 & 0.0634 & -7.6948 & -5.5190 \\
\hline 20 & 0.0516 & -6.6596 & -4.8566 \\
\hline 30 & 0.0335 & -5.4703 & -4.0838 \\
\hline 45 & 0.0212 & -4.4847 & -3.4243 \\
\hline 60 & 0.0166 & -3.8858 & -3.0051 \\
\hline
\end{tabular}

In table $1, \mathrm{Z}$ statistics are beyond the $95 \%$ confidence interval, [1.96, 1.96] no matter $r_{t}$ is homoscedastic or heteroscedastic. Therefore, we refuse the null hypothesis, namely the index is not in conformity with the random walk. At the same time, along with the extension of lag phase, the absolute value of $Z$ statistic gradually reduced, but it is not in the confidence interval until the $q=60$. In these factors which cause deviation of price, noise is the most important one, variance ratio test confirmed the existence of noise trading in SHSE A-share index.

\section{B. Heteroscedasticity Test}

It's necessary to test the stationarity of data before the regression model is established. To take the natural logarithm of SHSE A-share index and make ADF unit root test. Upon examination, the probability that data has unit root is $\mathrm{P}=0.0112$. As a result, the SHSE A-share index is stable, the regression model can be established.

As mentioned above, in order to overcome the nonstationary of raw data, we need to get logarithmic index, and get the following regression the closing price of day $t$ and day $t-1$ :

$$
\ln p_{t}=c+\ln p_{t-1}+u_{t}
$$

Where $u_{t}$ is residual, $c$ is constant term. The result which makes use of least squares estimation is obtained: 


$$
\begin{aligned}
\ln \left(\hat{p}_{t}\right)=0.0694+0.9911 \times \ln \left(p_{t-1}\right) \\
\mathrm{t}=(3.36) \quad(378.57) \\
R^{2}=0.992 \quad \text { AIC }=-5.179 \quad \mathrm{SC}=-5.170
\end{aligned}
$$

It is clear that the fitting equation is very effective, however, we have to test the heteroscedasticity of the residual error of equation $u_{t}$, due to heteroscedasticity will make an evident impact on variance ratio and the time series model. Intuitively, fig. 1 is a residual's figure of regression equation, the figure shows that the yield $r_{t}$ is very volatile in a period and fluctuation in another period is very small, it shows that heteroscedasticity exists in residual.

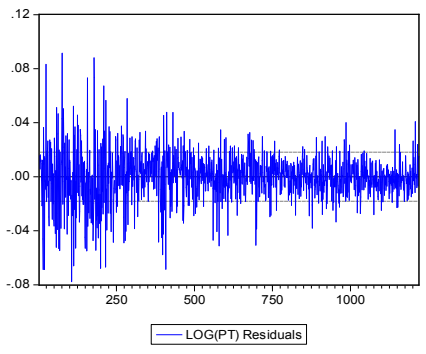

Figure 1. Residual figure

Due to heteroscedasticity exists in residual, the $\mathrm{ARCH}$ LM test must be used to verify necessarity of use conditional heteroscedastic model to modify the regression model. The ARCH LM test result is shown in table 2, lag phase $p=1$. The table shows that we should reject the null hypothesis, namely the ARCH effect exists in the residual.

TABle 2. Test Result of ARCH LM

\begin{tabular}{llll}
\hline $\mathrm{F}$ & 32.032 & $\mathrm{P}$ & 0.0000 \\
$T \times R^{2}$ & 31.260 & $\mathrm{P}$ & 0.0000 \\
\hline
\end{tabular}

\section{EGARCH-M Model}

It's confirmed that the series of SHSE A-share index has $\mathrm{ARCH}$ effect, in order to make a quantitative description about the asymmetric effect on the stock market, we need to set up EGARCH-M model. It is worth noting that the EGARCH model established by Eviews is different from Nelson's: first is the presumption that the conditional distribution of error term $u_{t}$ is different; Second, conditional variance of Eviews is defined as:

$$
\ln \left(\sigma_{t}^{2}\right)=\omega+\beta \ln \left(\sigma_{t-1}^{2}\right)+\alpha\left|\frac{u_{t-1}}{\sigma_{t-1}}\right|+\gamma \frac{u_{t-1}}{\sigma_{t-1}}
$$

Thus, the difference between identified equations of Eviews and Nelson is located in the constant term, it does not affect the final conclusion. Where $\gamma$ is on behalf of the size of the asymmetric effect. If $\gamma$ isn't close to 0 significantly, asymmetry exists in shock. This paper takes SHSE A-share index between January 2008 and June 2013 as sample, EGARCH-M model is set up by Eviews6.0. Condition mean equation of the model established is as follows:

$$
\ln p_{t}=\mu+\rho \ln p_{t-1}+\varphi \ln \sigma_{t}^{2}+u_{t}
$$

The result is:

Mean equation:

$$
\begin{aligned}
\ln \hat{p}_{t} & =0.0957+0.9896 \times \ln p_{t-1}+0.0017 \ln \sigma_{t}^{2} \\
\mathrm{Z} & =(5.72)
\end{aligned}
$$

Variance equation:

$$
\begin{gathered}
\ln \left(\sigma_{t}^{2}\right)=-0.1519+0.9919 \ln \left(\sigma_{t-1}^{2}\right)+0.1120\left|\frac{u_{t-1}}{\sigma_{t-1}}\right| \\
-0.0159 \frac{u_{t-1}}{\sigma_{t-1}} \\
\mathrm{z}=\quad \begin{array}{ccc}
(-4.86) \quad(331.87) & (6.90) \quad(-1.98) \\
R^{2}= & 0.992 \quad \text { AIC }=-5.42 \quad \mathrm{SC}=-5.39
\end{array}
\end{gathered}
$$

Compared with equation (5), $\mathrm{AIC}$ and $\mathrm{SC}$ become smaller, so it fits the model more effectively by adding $M$ item in the mean equation, the effectiveness of equation is improved. The empirical result of model shows that $\gamma$ is not close to 0 significantly, indicates that there is asymmetry in SHSE A-share market, namely, bad news make larger fluctuation, and there is leverage effect in daily closing price of SHSE A-share index.

\section{The Information Impact Curve}

Using EGARCH-M model, we can show the asymmetric effect of information on stock price intuitively through curve drawing of asymmetric information's impact. Information impact curve was proposed by Z. Ding, G. Clive and E. F. Robert in 1993 [17]. Fig. 2 is the information impact curve of SHSE A-share which is based on the model.

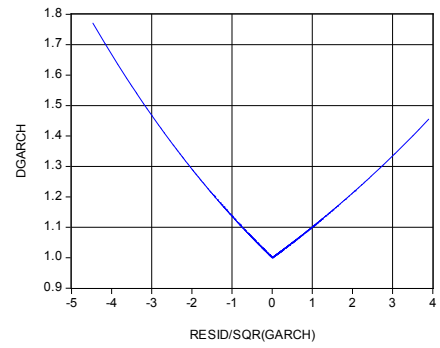

Figure 2. Impact curve of information

The figure shows that when the value of the error term $\hat{u}_{t}$ is negative, the curve is relatively steep; otherwise, the curve is relatively flat. It can be concluded that the impact of negative information is fiercer than positive information.

\section{E. Measure Index of Noise Risk}

First of all, it is necessary to define the different compositions of volumes. The mixed distribution hypothesis proposed by $\mathrm{P}$. K. Clark in 1973 regarded the trading volumes as the embodiment of the information flow [18].On the basis, A. G. Torben put forward the information volume and the non-information volume for the first time [19]. Therefore, this article takes the volatility of daily stock price as impact of trading behavior on it, the impact includes three parts: information volume, this is generated by historical information and instant information; non-information volume which is caused by other factors, such as the 
liquidity needs of traders; noise trading, this is the result of that investors who regard noise as information.

In the fitting result of EGARCH-M model, residual $u_{t}$ contains the part that stock price (index) cannot be changed by history information (including residual, conditional variance, etc.). In addition, the mean of residual in $K$ days $\bar{u}_{K}$ includes the impact of temporary good or bad news on stock price, and the part is come from the impact of the irrational behavior of investors.

We take $u_{t}-\bar{u}_{K}$ as offset of residual at day $t$ in regression model, where $\bar{u}_{K}$ stands for the moving average volume of residual item in a certain period. Because the moving average of residual item reflects the impact of historical information on stock prices, we take $\Delta_{t}=u_{t}-\bar{u}_{K}$, namely, the residual offset is on behalf of noise trading's impact on share prices.

Considering the stock market has 20 trading days only a month, we take $K=20$. When $q=20$, the result of variance ratio test is: $\operatorname{VR}(20)=0.0508, \mathrm{Z}_{1}(20)=-10.7665$, $Z_{2}(20)=-7.8017$, the share price does not conform the random walk hypothesis, either.

The mean equation of EGARCH-M model is as follows:

$$
\ln p_{t}-\ln \hat{p}_{t}=u_{t}=\bar{u}_{K}+\Delta_{t}
$$

Because this article is going to explore the impact of $\Delta_{t}$ on the stock price, so we take a deformation of above equation. Transpose and make the logarithm of both sides:

$$
p_{t} /\left(\hat{p}_{t} e^{\bar{u}_{K}}\right)=e^{\Delta_{t}}
$$

Assume that error $\phi_{t}$ exists in the estimation of price in the model, namely $\hat{p}_{t}=p_{t}\left(1-\phi_{t}\right)$. Because $e^{\bar{u}_{K}}$ does not change and significantly close to 1 over time, the relationship between $\phi_{t}$ and $e^{\Delta_{t}}$ is as follows:

$$
\phi_{t} \approx 1-1 / e^{\Delta_{t}}
$$

Accordingly, there is a direct relationship between the deviation of stock price and fluctuations caused by noise. We can calculate the deviation rate $\phi_{t}$ by measuring the residual deviation $\Delta_{t}$.

So, $e^{\Delta_{t}}$ is behalf of the impact of noise. It can be named as Noise Impact (NI) as well, namely noise impact of day is as follows:

$$
N I_{t}=e^{\Delta_{t}}=e^{u_{t}-\bar{u}_{K}}
$$

In order to describe the impact of unit standard deviation preferably, and conditional variance reflects the risk of noise impact, so we establish measure index with the help of the thoughts of a Sharp Rate [20], namely $\left(u_{t}-\bar{u}_{K}\right) / \sigma_{t}$. It might be named Noise Risk Rate (NRR) as well, its expression is:

$$
N R R_{t}=\left(u_{t}-\bar{u}_{K}\right) / \sigma_{t}
$$

Their relationship is:

$$
N R R_{t}=\ln N I_{t} / \sigma_{t}
$$

Where the risk rate of noise $N R R$ is the ratio between the logarithm of noise impact, $\ln N I_{t}$ and standard deviation, $\sigma_{t}$. Applying Eviews software, the value of $N I$ and $\sigma_{t}$ can be obtained easily, so noise risk rate can be figured out to determine the size of the noise risk in stock market.

\section{MEASURE OF NOISE COMPONENT}

In previous sections, EGARCH-M model has verified the asymmetric impact of information on stock price. On the other hand, the impact of noise also reflects on the unexpected change of trading volume. For individual stocks, the information impact on trading volume is embodied in fluctuations of turnover rate. The impact on turnover rate also has asymmetry effect because of the irrational factors, namely turnover rate can be greatly improved by positive information, while the impact of bad news is small relatively.

In this section, we select several shares listed in SHSE Ashare whose provides overall is large, time of going public is long, and then carry on the regression analysis by EGARCH$\mathrm{M}$ model, then get the measure index of noise components on the basis. The turnover rate daily is influenced by previous turnover rate and yield rate, so we choose them as independent variables.

For limited space, this paper show the fitting results of $600000,600006,600015,600019$ and 600015 only, it's verified that most of the stocks are appropriate for the model. In this paper, the selection of data is daily turnover rate of individual stocks, the data source is Resset database. Because the turnover rate of new shares is high, and its fluctuation is large, the choice interval of data is the day after two months of IPO to June 2013.

Before the establishment of regression model, we need to take unit root test to turnover rate, Turnover $_{t}$ and yield of stock, $r_{t}$, test results are shown in table 3 . It shows that there is no unit root in daily turnover rate of five stocks, so the regression model can be established.

TABLE 3. Results of ADF Unit RoOt Test

\begin{tabular}{c|c|r|c}
\hline Variable & stock & ADF value & P \\
\hline \multirow{4}{*}{ Turnover $_{t}$} & 600000 & -5.20 & 0.0000 \\
\cline { 2 - 4 } & 600006 & -4.56 & 0.0002 \\
\cline { 2 - 4 } & 600015 & -5.46 & 0.0000 \\
\cline { 2 - 4 } & 600019 & -6.89 & 0.0000 \\
\cline { 2 - 4 } & 600029 & -8.97 & 0.0000 \\
\hline \multirow{5}{*}{$r_{t}$} & 600000 & -55.95 & 0.0001 \\
\cline { 2 - 4 } & 600006 & -42.75 & 0.0000 \\
\cline { 2 - 4 } & 600015 & -48.64 & 0.0001 \\
\cline { 2 - 4 } & 600019 & -52.72 & 0.0001 \\
\cline { 2 - 4 } & 600029 & -43.29 & 0.0000 \\
\hline \multicolumn{3}{|c|}{ Note: ADF test options are intercept term and excluding trend. } \\
\hline
\end{tabular}

First of all, we can assume that there is linear relationship between turnover rate of day $t$ and the day before $t$. Linear model is as follows:

$$
\text { Turnover }_{t}=c+\theta_{1} \text { Turnover }_{t-1}+\theta_{2} r_{t}+u_{t}
$$

Where Turnover $r_{t}$ stands for turnover rate at day $t, u_{t}$ is residual. The results are listed in table 4 . 
TABle 4. THE RESUlts of REgRESSION MODEL FOR TURNOVER RATE

\begin{tabular}{c|c|c|c|c|c|c|c|c}
\hline STOCK & $c^{*}$ & $\theta_{1}{ }^{*}$ & $\theta_{2}{ }^{*}$ & $R^{2}$ & $\mathrm{~F}^{*}$ & A.W. & SC \\
\hline 600000 & $\begin{array}{c}0.072 \\
(12.096)\end{array}$ & $\begin{array}{c}0.824 \\
(83.555)\end{array}$ & $\begin{array}{c}2.119 \\
(13.621)\end{array}$ & 0.698 & 3587.878 & 2.483 & 0.016 & 0.022 \\
\hline 600006 & $\begin{array}{c}0.104 \\
(11.170)\end{array}$ & $\begin{array}{c}0.828 \\
(90.480)\end{array}$ & $\begin{array}{c}5.704 \\
(22.112)\end{array}$ & 0.732 & 4377.312 & 2.249 & 1.115 & 1.121 \\
\hline 600015 & $\begin{array}{c}0.236 \\
(14.106)\end{array}$ & $\begin{array}{c}0.759 \\
(57.889)\end{array}$ & $\begin{array}{c}5.728 \\
(16.387)\end{array}$ & 0.628 & 1827.125 & 2.409 & 1.420 & 1.428 \\
\hline 600019 & $\begin{array}{c}0.059 \\
(12.667)\end{array}$ & $\begin{array}{c}0.811 \\
(76.614)\end{array}$ & $\begin{array}{c}1.295 \\
(12.694)\end{array}$ & 0.680 & 3035.230 & 2.387 & -0.652 & -0.646 \\
\hline 600029 & $\begin{array}{c}0.192 \\
(16.683)\end{array}$ & $\begin{array}{c}0.703 \\
(48.731)\end{array}$ & $\begin{array}{c}3.062 \\
(14.839)\end{array}$ & 0.541 & 1299.854 & 2.253 & 0.531 & 0.539 \\
\hline
\end{tabular}

The we should take ARCH LM test for residual. Test results are shown in table 5. It shows that ARCH effect exists in the residuals of regression. We need deal with conditional heteroscedasticity.

TABLE 5. THE TEST RESUltS OF ARCH EFFECT

\begin{tabular}{c|r|r}
\hline Stock code & \multicolumn{1}{|c|}{$\mathbf{F}^{*}$} & \multicolumn{1}{c}{$T \times R^{2}{ }^{*}$} \\
\hline 600000 & 67.983 & 130.380 \\
\hline 600006 & 237.493 & 413.983 \\
\hline 600015 & 92.244 & 88.563 \\
\hline 600019 & 155.147 & 147.275 \\
\hline 600029 & 39.676 & 76.766 \\
\hline \multicolumn{3}{|c}{ Note: * means statistics are significant at $1 \%$ level. }
\end{tabular}

\section{A. EGARCH-M Model and Information Impact Curve}

The test above shows that daily yield rate of individual stocks has ARCH effect obviously. Considering the asymmetry of information impact, this paper takes asymmetric EGARCH-M model as regression for individual stock.

Mean equation of model:

Turnover $_{t}=\mu+\rho_{1}$ Turnover $_{t-1}+\rho_{2} r_{t}+\varphi \ln \sigma_{t}^{2}+u_{t}$

Conditional variance equation:

$$
\ln \left(\sigma_{t}^{2}\right)=\omega+\beta \ln \left({\sigma_{t-1}}^{2}\right)+\alpha\left|\frac{u_{t-1}}{\sigma_{t-1}}\right|+\gamma \frac{u_{t-1}}{\sigma_{t-1}}
$$

The estimate results of EGARCH-M model for turnover rate of individual stocks are shown in table 6 . The premise of joining $\mathrm{M}$ item to the mean equation is that AIC and SC become smaller. Compared with table 4, the two values are smaller, so the mean equation is effective, namely we can join $\mathrm{M}$ item.

The regression results show that $\gamma$ is not 0 remarkably, so the impact of information on the turnover rate has asymmetry obviously. In the estimation results of EGARCH$\mathrm{M}$ model for five stocks, $\gamma>0$ at all the time, it implies the impact of good news on turnover rate is significantly greater than bad news.

It will display the asymmetry of information visually through drawing impact curve of information to turnover rate. In 600000, for example, the information impact curve is shown in fig. 3. The figure shows that the impact of good news on turnover rate is significantly greater than bad news.

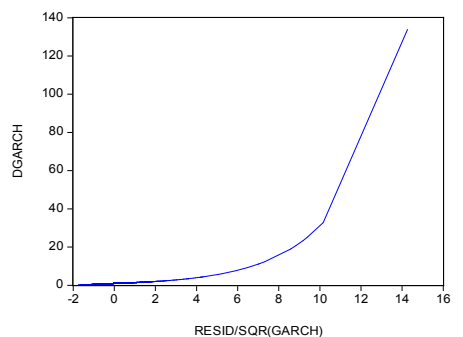

Figure 3. The impact curve of information (turnover rate)

\section{B. Measure of Noise Component}

Because the most direct embodiment of noise component [21] is the deviation of volume in stock market, and then causes the deviation of share price. In this paper, we can establish the measure index of noise component for imitating the method of measure of noise risk. The difference between residual item and mean of 20 days, $\Delta_{t}=u_{t}-\bar{u}_{20}$ can be described as Noise Component Index (NCI), it shows the percentage of noise trading in turnover rate. Now the measure index of noise component can be established, its expression is as follows:

$$
N C I_{t}=\frac{u_{t}-\bar{u}_{20}}{\text { Turnover }} \times 100
$$

Where $N I_{t}$ can be expressed as the percentage of deviation of turnover rate which is caused by noise. We need to pay attention to the following points for applying of $N C I$ indicators:

First of all, the absolute value of NCI may be larger than 100 , and even become very large. The deviation between residual error and mean $u_{t}-\bar{u}_{20}$ may be greater than turnover rate in the day. This kind of situation happens when turnover rate is close to zero, usually in daily limit of individual stocks. On the circumstance, we can't use this model to measure noise component, but the study of stock price in this model is not affected by the limitation; 
TABLE 6. Estimate Results OF EGARCH-M MODEL

\begin{tabular}{c|c|c|c|c|c}
\hline & $\mathbf{6 0 0 0 0 0}$ & $\mathbf{6 0 0 0 0 6}$ & $\mathbf{6 0 0 0 1 5}$ & $\mathbf{6 0 0 0 1 9}$ & $\mathbf{6 0 0 0 2 9}$ \\
\hline$\mu^{*}$ & 0.247 & 0.263 & 1.224 & 0.458 & 0.774 \\
& $(27.996)$ & $(17.414)$ & $(14.621)$ & $(19.355)$ & $(11.237)$ \\
\hline$\rho_{1} *$ & 0.661 & 0.7005 & 0.377 & 0.475 & 0.461 \\
& $(50.175)$ & $(67.918)$ & $(14.751)$ & $(19.279)$ & $(16.162)$ \\
\hline$\rho_{2}$ & 0.866 & 2.007 & 3.547 & 0.667 & 1.916 \\
& $(27.032)$ & $(17.857)$ & $(20.519)$ & $(15.305)$ & $(16.552)$ \\
\hline \multirow{2}{*}{$\varphi^{*}$} & 0.037 & 0.045 & 0.334 & 0.076 & 0.169 \\
& $(27.061)$ & $(13.443)$ & $(10.988)$ & $(18.676)$ & $(8.530)$ \\
\hline \multirow{2}{*}{$\omega^{*}$} & -0.252 & -0.213 & 10.988 & -0.250 & -0.259 \\
& $(-16.158)$ & $(-15.417)$ & $(-7.584)$ & $(-12.094)$ & $(-11.94732)$ \\
\hline \multirow{2}{*}{$\gamma^{*}$} & -0.218 & -0.187 & 0.029 & -0.054 & 0.100 \\
& $(-15.004)$ & $(-13.965)$ & $(3.113)$ & $(-5.305)$ & $(10.232)$ \\
\hline \multirow{2}{*}{$\beta *$} & 0.561 & 0.574 & 0.158 & 0.334 & 0.214 \\
& $(33.721)$ & $(33.851)$ & $(16.434)$ & $(43.545)$ & $(22.820)$ \\
\hline$R^{2}$ & 0.898 & 0.875 & 0.970 & 0.931 & 0.928 \\
\hline $\mathbf{A I C}$ & $(208.959)$ & $(147.694)$ & $(188.173)$ & $(160.517)$ & $(131.186)$ \\
\hline SC & 0.699 & 0.712 & 0.658 & 0.690 & 0.549 \\
\hline
\end{tabular}

Second, when NCI is negative, the residual is lower than the average residual error of the day. It suggests that the noise of market is eliminated, efficiency of information increases, turnover rate of stock decreased to normal gradually, stock price will recover to its own expected value.

Fig. 4 reflects the statistical properties of noise component index that is time series after getting rid of outliers. The figure shows that noise component of 600019 share is very low, its average is $7.4 \%$. On the other hand, the trading days whose noise component index distributes on both sides of 0 are in the majority. It is close to the actual market, so the measure index of component is reasonable.

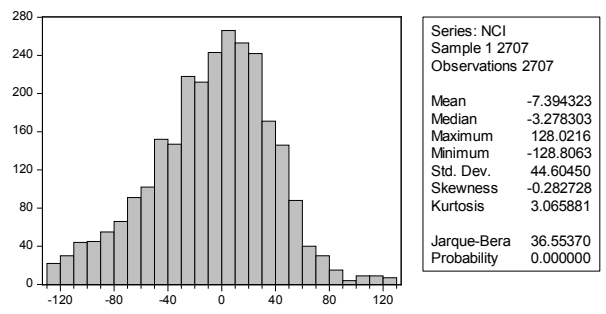

Figure 4. The statistical properties of noise component index(600019)

\section{CONCLUSION}

The traditional measure methods of noise trading were established on the basis of CAPM model which was unable to prove its practicality or BAPM model which was hard to quantify. So they all have complex calculation but low efficiency, and their feasibility is poor, they can't give reasonable measure of noise trading at econometrics level.

There are the following conclusions through above research:
Firstly, noise trading is ubiquitous in Chinese stock market, variance ratio test result has proven that the universal existence of noise trading, this is the main cause of low efficiency of market information in Chinese stock, and actually, many investors act as noise traders.

Secondly, the impact of good news and bad news on price and volume has asymmetry, EGARCH-M model is one of asymmetrical generalized ARCH models, and very effective in the reflex of the asymmetric impact of information. In this paper, the information impact curve has shown the different kinds of the noise impact on investor behavior and performance of stock market. Among them, the impact of bad news on the price of the stock market is bigger; and the impact of positive information on stock trading volume is more outstanding. It has deepen the previous research.

Thirdly, stock price and turnover rate have ARCH effect, EGARCH-M model will fit them effectively. We can establish measure indexes of noise risk and noise component through the model which can describe the noise of the market trading properly. About the application of the fitting results of this model, this article applies the method of Sharpe Ratio, to show the unit impact of noise risk on price and volume objectively, to enhance the practicability of this method.

The measure indexes of noise risk and noise component are able provide a new angle of view to the research of noise trading, the future research is diversified, such as how to apply these two measure indexes to research noise trading in stock market at the same time, and to explore the essence of their relationship, namely the price-volume relationship. 


\section{REFERENCES}

[1] F. Black, "Noise," The Journal of Finance, vol. 41, Jul. 1986, pp. 529 543, doi: 10.1111/j.1540-6261.1986.tb04513.x.

[2] D. J. Bradford, S. Andrei, S. L. Lawrence, W. Robert J. "The size and incidence of the losses from noise trading", The Journal of Finance, vol. 44(3), Jun. 1989, pp. 681-696, doi: 10.1111/j.15406261.1989.tb04385.x.

[3] D. James, G. Gary. "Noise traders", National Bureau of Economic Research, 2006.

[4] P. Frederic, "Noise trading in small markets", The Journal of Finance, vol. 51, Sep. 2012, pp. 1537-1550, doi: 10.1111/j.15406261.1996.tb04079.x.

[5] B. Gregory W, "Volatility, sentiment, and noise traders". Financial Analysts Journal, vol. 55, Apr. 1999, pp. 82-90.

[6] M. G. Burton, F. F. Eugene, "Efficient capital markets: a review of theory and empirical work", The journal of Finance, vol. 25, May 1970, pp. 383-417, doi: 10.1111/j.1540-6261.1970.tb00518.x.

[7] D. J. Bradford, "Noise trader risk in financial markets", University of California, Berkeley, 1990.

[8] S. Wang, W. Li, "The measure of noise trader risk based on BAPMan example of punished listed company", Operations Research and Management Science, Feb. 2012, vol. 21, pp. 167-174.

[9] B. Meng, "A study of index arbitrary limits caused by the noise trading risks", Journal of Luoyang Institute of Science and Technology( Social Science), vol. 26, Jun. 2011, pp. 46-48.

[10] X. Xiao, Z. Yuan, S. Chen, "Measure on NTR in BAPM model", Systems Engineering, vol. 29(10), Oct. 2011, pp. 103-107.

[11] X. Chen, A. Sun, "The test on validity of CAPM in China stock market" Journal of Beijing University (Philosophy and social sciences), vol. 37, Aug. 2000, pp. 28-37.
[12] Y. Zhou, X. Zhao, "Study on asymmetry of volatility of HK exchange rate based on GJR-GARCH", Journal of Hunan University of Technology, vol. 23, Nov. 2009, pp. 73-77.

[13] L. W. Andrew, M. A. Craig, "The size and power of the variance ratio test in finite samples: A Monte Carlo investigation", Journal of econometrics, vol. 40, Feb. 1989, pp. 203-238, doi: 10.1016/03044076(89)90083-3.

[14] E. F. Robert, "Autoregressive conditional heteroscedasticity with estimates of the variance of United Kingdom inflation", Econometrica: Journal of the Econometric Society, vol. 30, Jul. 1982, pp. $987-1007$.

[15] B. Tim, "Generalized autoregressive conditional heteroskedasticity", Journal of econometrics, vol. 31, Apr. 1986, pp. 307-327, doi: 10.1016/0304-4076(86)90063-1

[16] N. B. Daniel, "Conditional heteroskedasticity in asset returns: a new approach", Econometrica: Journal of the Econometric Society, vol. 59 Mar. 1991, pp. 347-370.

[17] Z. Ding, G. Clive, E. F. Robert, "A long memory property of stock market returns and a new model", Journal of empirical finance, vol. 1, Jun. 1993, pp. 83-106, doi: 10.1016/0927-5398(93)90006-D.

[18] P. K.Clark, "A subordinated stochastic process model with finite variance for speculative prices", Econometrica: Journal of the Econometric Society, vol. 41, Jan. 1973, pp. 135-155.

[19] A. G. Torben, "Return volatility and trading volume: An information flow interpretation of stochastic volatility", The Journal of Finance, vol. 51, Mar. 1996, pp. 169-204, doi: 10.1111/j.15406261.1996.tb05206.x.

[20] S. F. William, "The sharpe ratio", Portfolio Management, Princeton University Press Princeton, New Jersy, vol. 21, 1998, pp. 169-185.

[21] D. Kong, "Noise composition test of stock prices with NCT: evidence from seven Asian stock markets", Chinese Journal of Management Science, vol. 13, Dec. 2005, pp. 6-10. 